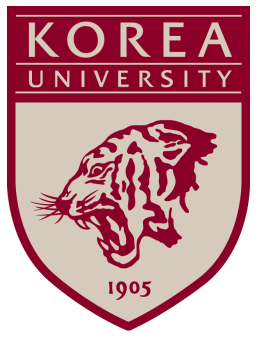

Discussion Paper Series

No. 1308

Dec 2013

\title{
Constrained or Unconstrained Price for Debit Card Payment?
}

\author{
Manjong Lee
}

The Institute of Economic Research - Korea University

Anam-dong, Sungbuk-ku, Seoul, 136-701, South Korea, Tel: (82-2) 3290-1632, Fax: (82-2) 928-4948 Copyright (c) 2013 IER. 


\title{
Constrained or Unconstrained Price for Debit Card Payment?
}

\author{
MANJong LeE \\ Department of Economics \\ Korea University \\ Seoul, Korea \\ manjong@korea.ac.kr
}

\begin{abstract}
Retailers in the Netherlands and the U.K. can charge different prices for a commodity depending on whether cash or a debit card is used as payment, whereas retailers in the U.S. generally cannot. These two types of economies with and without a uniform pricing constraint for cash and debit card payments are compared in a microfounded monetary model. We place particular emphasis on the distinctive features of cash and debit cards as payment methods: the cost of a cash transaction for the seller is typically lower than that of a debit card, whereas the cost of cash holdings for the buyer is higher than that of a debit card. Our results suggest that a uniform pricing constraint makes cash-holding costs decline but consumption dispersion between the poor and the rich increase. Numerical examples show that the beneficial effect of the constraint dominates its negative effect.
\end{abstract}

Keywords: cash, debit card, constrained price, unconstrained price JEL classification: D61, E42, E64 


\section{Introduction}

In the shift from paper-based to electronic transactions, the debit card has emerged as one of the primary means of payment. According to Borzekowski, Kiser and Ahmed (2008), debit card transactions have grown at an average rate of more than 20 percent per year since 1996. Schuh and Stavins (2012) report that debit cards made up the largest share of monthly payments in the 2008 Survey of Consumer Payment Choice.

The increased use of debit cards has drawn the attention of policymakers to the debit card industry. For instance, in October 2011, the Federal Reserve Board introduced Regulation II which placed a cap on the debit card interchange fee paid from a retailer's bank to a consumer's bank. This fee is of particular interest because it could be passed on to consumers via higher retail prices. Retailers in the U.S. are not typically allowed to impose a surcharge for purchases made using debit cards, hence they usually charge the same price for both cash and debit card payments. ${ }^{1}$ Sellers are therefore likely to pass on debit card processing costs as higher prices for all consumers regardless of payment method, which then has regressive distributional implications. That is, in an economy where the poor typically use cash rather than debit cards, they will eventually subsidize the cost of debit card transactions, a payment method more commonly used by the rich.

This potential channeling of transaction costs through to consumers not involved in those transactions has sparked concern over the consequences for consumption and welfare, especially compared to economies such as the Netherlands and the U.K. where retailers can charge different prices contingent on the payment method used. In order to shed light on this issue, this paper compares an economy employing a uniform price constraint for cash and debit card payments (a constrained-price economy) with an economy not imposing the constraint (an unconstrained-price economy).

\footnotetext{
${ }^{1}$ Since January 2013, the retailers in 40 U.S. states have been permitted to apply a surcharge to credit card purchases ("checkout fee"), but they cannot impose it for purchases made using debit or prepaid cards.
} 
Most industrial organization literature that addresses these two economies focuses on the characteristics of the payment industry, including demand elasticities for payment services, competitions among sellers and among payment-service providers, and externalities attributed to payment networks. ${ }^{2}$ Rather than revisiting these issues, we focus on the payments policy question: whether or not government should allow retailers to charge different prices across cash and debit card transactions. Put differently, industrial organization does not enter into our analysis. Instead, we make comparisons between the two ideal systems, one where price uniformity is enforced and the other where it is not. In doing so, we place particular emphasis on the distinctive features of cash and debit cards as payment methods: the cost of a cash transaction for the seller is typically lower than that of a debit card, whereas the cost of cash holdings for the buyer is usually higher than that of a debit card due to the inconvenience of carrying cash around and the risk of loss or theft (for more discussion, see Humphrey 2004, He, Huang and Wright 2008, and Monnet and Roberds 2008).

Our main results are as follows. We first show that if the transaction cost of a debit card is neither too large nor too small and agents are sufficiently patient, there are equilibria wherein the poor use cash and the rich use debit cards in a constrained-price economy, whereas the poor use cash and the rich use both cash and debit cards in an unconstrained-price economy. We pay keen attention to these equilibria because their properties are plausible enough in the following senses. First of all, they suggest that the proportion of debit card transactions in a constrained-price economy is higher than in an unconstrained-price economy, which is consistent with the empirical observations of Bolt, Jonker and van Renselaar (2010). In addition, because cash users (the poor) in a constrained-price economy eventually share the transaction cost of debit cards, consumption by the rich (debit-card users) is larger in a constrained-price economy than in an unconstrained-price economy, whereas consumption by the poor is larger in an unconstrained-price economy than in a constrained-price economy.

\footnotetext{
${ }^{2}$ More details, see Hunt (2003), Rochet and Tirole (2004, 2006), Bolt, Jonker and van Renselaar (2010), and Chakravorti (2010).
} 
This essentially conforms to the results of Carlton and Frankel (1995), Schwartz and Vincent (2006), and Schuh, Shy and Stavins (2010).

We then compare the welfare inherent in the constrained-price and the unconstrainedprice equilibria, where welfare is defined as the lifetime expected discounted utility of a representative agent. Since the terms of trade for cash payments are more favorable than those for debit card payments in an unconstrained-price economy, an agent in an unconstrainedprice economy is willing to hold more cash than in a constrained-price economy. Hence the cost incurred due to cash holdings is higher in an unconstrained-price economy than in a constrained-price economy. On the other hand, the consumption dispersion increases in a constrained-price economy compared to an unconstrained-price economy because in a constrained-price economy, consumption by the poor is relatively small and consumption by the rich is relatively large. These, together with a concave utility function, imply that the overall welfare ranking of the two economies relies on the relative magnitude of the cost-saving effect of holding cash in a constrained-price economy and the consumptionsmoothing effect in an unconstrained-price economy. Using a wider range of parameter values, we do some numerical exercises. In every case considered, the cost-saving effect of holding cash in a constrained-price economy dominates the consumption-smoothing effect in an unconstrained-price economy. This provides support for uniform pricing across cash and debit card payments.

The paper proceeds as follows. Section 2 describes the model economy, followed by equilibrium characterization in Section 3. Section 4 compares a constrained-price equilibrium with an unconstrained-price equilibrium and Section 5 summarizes the paper with a few concluding remarks. Appendix contains the proofs of the analytical results and the details of the numerical results. 


\section{Model}

The background environment is that of Lagos and Wright (2005) with competitive markets as in Berentsen, Camera and Waller (2005). ${ }^{3}$ Time is discrete and the horizon is infinite. There is a $[0,1]$ continuum of infinitely-lived agents with one perishable and divisible good which can potentially be produced and consumed by all agents. There is also an intrinsically useless, divisible and durable object called money. Each agent is endowed with $M>0$ units of money at the beginning of the initial period. In each period, agents trade in three Walrasian markets, called market 1, 2, and 3, which open and close sequentially.

The sequence of events in a typical period is as follows. When entering market 1 with a given amount of money, an agent becomes either a buyer with probability $\rho_{b}>0$ or a seller with probability $\rho_{s}=\left(1-\rho_{b}\right)>0$. As a buyer, an agent obtains utility $u(q)$ from consuming $q \in \mathbb{R}_{+}$units of good where $u^{\prime \prime}<0<u^{\prime}, u^{\prime}(\infty)=0, u(0)=0$, and $u^{\prime}(0)=\infty$. As a seller, an agent suffers disutility $q$ from producing $q \in \mathbb{R}_{+}$units of good.

With the money balance after trading in market 1, agents move on to market 2 where each agent again receives an idiosyncratic trading shock so that she will become either a buyer or a seller with equal probability. After the realization of the preference shock for market 2, the government has access to intra-market record-keeping technology and begins to provide a checkable deposit service. Each agent then chooses a portfolio $\boldsymbol{\omega}=(c, d) \in \mathbb{R}_{+}^{2}$ where $c$ and $d$ denote cash holdings and checkable deposits respectively. An agent holding cash incurs disutility $\varphi \in(0,1)$ for each unit of real cash balance. This disutility cost can be interpreted as capturing not only the inconvenience of carrying cash around and the risk of loss or theft, but also the opportunity costs such as interest on checkable deposits (see, for instance, He, Huang and Wright 2008, Kim and Lee 2010, and Yi 2011). ${ }^{4}$ There is no

\footnotetext{
${ }^{3}$ Related competitive pricing models in the Lagos-Wright framework include Rocheteau and Wright (2005), Lagos and Rocheteau (2005), and Berentsen, Camera and Waller (2007).

${ }^{4}$ Because the checkable-deposit service is not available in market 1 and 3 , introducing a cash-holding cost in those markets would have no impact in the comparison of an unconstrained-price and a constrained-price
} 
such cost if it is carried in the form of a checkable deposit; i.e., an agent making a deposit carries a debit card that causes negligible inconvenience. However, there is a minimum requirement to open an account and $\bar{d}$ amount of money should be deposited at the point of opening an account. This is a widespread practice in the real world and also leads to the readily observable prediction that sufficiently poor agents do not hold checking accounts. As in market 1 , a buyer gets utility $u(q)$ from consuming $q$ units of good and a seller suffers disutility $q$ from producing $q \in \mathbb{R}_{+}$units of good.

In this market, a seller accepting debit card payments incurs the extra cost $\eta \in(0,1)$ for each unit of debit card transaction. If a buyer uses a debit card, the government withdraws the purchase price from the buyer's account and transfers it to the seller in cash minus the cost. From a real-world perspective, this cost can be interpreted as the merchant fee paid by retailers to a card company that is left out from our model to avoid unnecessary complexity. That is, since our interest does not lie in the issues for a card company, we do not introduce it into the model explicitly. Instead, we simply assume that the government intermediates payment services and for the sake of an exogenous card company she collects the transaction cost of debit cards from the sellers who accept debit cards. In an economy where a uniform pricing constraint for cash and debit card payments is not imposed, a seller can charge the transaction cost of debit cards to the buyers using debit cards, whereas a seller cannot in an economy where the constraint is imposed. After the trade in market 2 but before moving onto market 3 , the government redeems the balance in the checking account in exchange for an associated debit card and information about the accounts is then erased.

We should note here that the trading histories across markets are private because the government can only keep the information about checking accounts within market 2 . An intra-market record-keeping technology also implies that the government cannot provide any loans or credit using the deposits because the records disappear at the end of market 2 and thus cannot be rolled over to the next market. These, together with the absence of economy. 
commitment and enforcement, make a tangible medium of exchange essential. ${ }^{5}$

At the beginning of market 3, the government injects money via lump-sum transfers to replenish the money confiscated through debit card transaction fees in the previous market. This conveniently sets the available stock of money in market 3 at a fixed level for each period. All agents in market 3 can consume, produce, and get utility $U(q)$ from consuming $q \in \mathbb{R}_{+}$units of good and suffer disutility $q$ from producing $q \in \mathbb{R}_{+}$units of good where $U^{\prime \prime}<0<U^{\prime}, U^{\prime}(\infty)=0, U(0)=0$, and $U^{\prime}(0)=\infty .{ }^{6}$ The discount factor across periods is $\beta \in(0,1)$

It is worthwhile to note that although the key factors associated with our main interest are concentrated in market 2 , market 1 and 3 are still indispensable. The trades in market 1 generate a nondegenerate distribution of money holdings at the beginning of market 2, which allows some agents to use cash and others to use debit cards in market 2. Meanwhile, it is well known that the trades in market 3 yield a degenerate distribution of money holdings, which greatly simplifies the analysis.

\section{Stationary Equilibrium}

We here focus on a stationary and symmetric equilibrium in which the end-of-period real money balance is constant over time with the fixed stock of money $M$.

\subsection{Unconstrained-Price Economy}

We first study an economy which does not introduce a uniform pricing constraint for cash and debit card payments. Let $p_{j, t}$ and $q_{j, t}$ denote respectively the price and quantity of good traded in market $j \in\{1,2,3\}$ in period $t$, and let $\phi_{t}=1 / p_{3, t}$, the price of money in terms

\footnotetext{
${ }^{5}$ See, for example, Kocherlakota (1998), Wallace (2001), Corbae, Temzelides and Wright (2003), and Aliprantis, Camera and Puzzello (2007).

${ }^{6}$ As discussed in Berentsen, Camera and Waller (2005), the different preference in market 3 is simply a technical device to ensure a degenerate distribution at the beginning of each period.
} 
of market-3 good. Let also $V_{j}\left(m_{j}\right)$ be the value function for an agent with $m_{j}$ amount of money when entering the market $j$. We will henceforth drop the time subscript $t$ and index the next-period variable by +1 if there is no risk of confusion. We formulate an equilibrium in a recursive manner and work backward from market 3 to market 1 .

The lifetime utility of an agent entering market 3 with $m_{3} \in \mathbb{R}_{+}$amount of money is given by

$$
\begin{array}{r}
V_{3}\left(m_{3}\right)=\max _{\left(q_{3}^{b}, q_{3}^{s}, m_{1,+1}\right)}\left[U\left(q_{3}^{b}\right)-q_{3}^{s}+\beta V_{1}\left(m_{1,+1}\right)\right] \\
\text { s.t. } q_{3}^{b}+\phi m_{1,+1}=q_{3}^{s}+\phi\left(m_{3}+\tau\right)
\end{array}
$$

where $q_{3}^{b}\left(q_{3}^{s}\right)$ is consumption (production) in market 3 and $\tau$ is a lump-sum transfer by the government. Substituting $q_{3}^{s}$ from the constraint, we have

$$
V_{3}\left(m_{3}\right)=\phi\left(m_{3}+\tau\right)+\max _{\left(q_{3}^{b}, m_{1,+1}\right)}\left[U\left(q_{3}^{b}\right)-q_{3}^{b}-\phi m_{1,+1}+\beta V_{1}\left(m_{1,+1}\right)\right]
$$

The first-order conditions for $\left(q_{3}^{b}, m_{1,+1}\right) \in \mathbb{R}_{++}^{2}$ and an envelope condition are respectively

$$
\begin{aligned}
& U^{\prime}\left(q_{3}^{b}\right)=1 \\
& \phi=\beta V_{1}^{\prime}\left(m_{1,+1}\right) \\
& V_{3}^{\prime}\left(m_{3}\right)=\phi .
\end{aligned}
$$

As in Lagos and Wright (2005), all agents consume $q_{3}^{b}=q_{3}^{*}=\arg \max \left[U\left(q_{3}^{b}\right)-q_{3}^{b}\right]$ regardless of $m_{3}$ and exit market 3 with an identical balance of money. This conveniently allows us to restrict our attention to cases where the distribution of money holdings is degenerate at the beginning of each period.

We next turn to market 2 . The lifetime utility of an agent entering market 2 with 
$m_{2} \in \mathbb{R}_{+}$amount of money is given by

$$
V_{2}\left(m_{2}\right)=\frac{1}{2}\left[V_{2}^{b}\left(m_{2}\right)+V_{2}^{s}\left(m_{2}\right)\right]
$$

where $V_{2}^{b}\left(m_{2}\right)$ and $V_{2}^{s}\left(m_{2}\right)$ denote the value as a buyer and as a seller respectively, which can be expressed as

$$
\begin{gathered}
V_{2}^{b}\left(m_{2}\right)=\max _{\left(q_{2, c}^{b}, q_{2, d}^{b}\right)}\left[u\left(q_{2, c}^{b}+q_{2, d}^{b}\right)+V_{3}\left(c-p_{2, c} q_{2, c}^{b}+d-p_{2, d} q_{2, d}^{b}\right)\right] \\
-\varphi\left[\left(m_{2} / p_{2, c}\right) \mathbf{1}_{\left\{m_{2}<\bar{d}\right\}}+\left(c / p_{2, c}\right) \mathbf{1}_{\left\{m_{2} \geq \bar{d}\right\}}\right] \\
V_{2}^{s}\left(m_{2}\right)=\max _{\left(q_{2, c}^{s}, q_{2, d}^{s}\right)}\left[-\left(q_{2, c}^{s}+q_{2, d}^{s}\right)+V_{3}\left(c+p_{2, c} q_{2, c}^{s}+d+(1-\eta) p_{2, d} q_{2, d}^{s}\right)\right] \\
-\varphi\left[\left(m_{2} / p_{2, c}\right) \mathbf{1}_{\left\{m_{2}<\bar{d}\right\}}+\left(c / p_{2, c}\right) \mathbf{1}_{\left\{m_{2} \geq \bar{d}\right\}}\right] .
\end{gathered}
$$

Here $q_{2, c}$ and $q_{2, d}$ denote the quantity of good traded via cash and debit cards respectively, $p_{2, c}$ and $p_{2, d}$ are the price of good when it is traded via cash and debit cards respectively, $\eta p_{2, d} q_{2, d}^{s}$ is the debit card transaction fee held by the government, and $\mathbf{1}_{\{\varkappa\}}$ is an indicator function taking a value of 1 if $\varkappa$ is true and 0 otherwise.

Taking the prices $\left(p_{2, \kappa}\right)_{\kappa \in\{c, d\}}$ as given, a buyer chooses $\left(q_{2, \kappa}^{b}\right)_{\kappa \in\{c, d\}}$ and a seller chooses $\left(q_{2, \kappa}^{s}\right)_{\kappa \in\{c, d\}}$. Specifically, a seller solves the right-hand side of (7), which yields the following optimality conditions:

$$
\begin{aligned}
p_{2, c} & =\phi^{-1} \\
p_{2, d} & =[(1-\eta) \phi]^{-1} .
\end{aligned}
$$

Similarly, a buyer solves the right-hand side of (6). Since $p_{2, c}<p_{2, d}$, a standard peckingorder of payment holds; i.e., as a payment method, a buyer uses cash first and then uses a debit card, if necessary (see, for instance, Freeman and Kydland 2000). This gives the 
following maximization conditions for $\left(q_{2, c}^{b}, q_{2, d}^{b}\right)$ respectively:

$$
\begin{aligned}
& u^{\prime}\left(q_{2, c}^{b}\right)=\left(\phi+\lambda_{c}\right) p_{2, c} \\
& u^{\prime}\left(q_{2, c}^{b}+q_{2, d}^{b}\right)=\left(\phi+\lambda_{d}\right) p_{2, d}
\end{aligned}
$$

where $\lambda_{c}$ and $\lambda_{d}$ are the Lagrange multipliers on the buyer's cash constraint $\left(p_{2, c} q_{2, c}^{b} \leq c\right)$ and the checkable deposit constraint $\left(p_{2, d} q_{2, d}^{b} \leq d\right)$ respectively. Using (8) and (9), (10) and (11) reduce to

$$
\begin{aligned}
& u^{\prime}\left(q_{2, c}^{b}\right)=1+\frac{\lambda_{c}}{\phi} \\
& u^{\prime}\left(q_{2, c}^{b}+q_{2, d}^{b}\right)=\frac{1}{1-\eta}\left(1+\frac{\lambda_{d}}{\phi}\right) .
\end{aligned}
$$

Let $\bar{q}_{2, c}$ and $\bar{q}_{2}$ be the solutions to (12) and (13) with $\lambda_{c}=0$ and $\lambda_{d}=0$ respectively.

Turning to the portfolio choice stage, let $\mathbf{a}_{m_{2}}^{b} \in \mathbb{R}_{+}^{2}$ be a portfolio chosen by an agent with $m_{2}$ as a buyer and let $\mathbf{a}_{m_{2}}^{s} \in \mathbb{R}_{+}^{2}$ be a portfolio chosen by an agent with $m_{2}$ as a seller. Notice first that due to the minimum requirement for opening an account, only agents with $m_{2} \geq \bar{d}$ can access the checkable deposit service. As a seller, an agent will choose $\mathbf{a}_{m_{2}}^{s}=\left(0, m_{2}\right)$ to save the cash-holding cost, whereas as a buyer, an agent will choose $\mathbf{a}_{m_{2}}^{b}=\left(c, m_{2}-c\right)$ where from (6), $c \in \mathbb{R}_{++}$should satisfy

$$
\frac{\varphi}{p_{2, c}} \leq\left(\frac{1}{p_{2, c}}-\frac{1}{p_{2, d}}\right) u^{\prime}\left(c / p_{2, c}\right)=\left(\frac{\eta}{p_{2, c}}\right) u^{\prime}\left(c / p_{2, c}\right)
$$

which can be simplified as

$$
\varphi \leq u^{\prime}\left(c / p_{2, c}\right) \eta
$$

Let $\bar{c}$ be the solution to (14) with equality that holds if the constraint $\left(c \leq m_{2}\right)$ is inactive. The left-hand side of (14) represents the marginal cost of holding cash compared to making a deposit, and the right-hand side represents the marginal return from trading using cash 
rather than a debit card. Notice that the demand for cash increases with the debit card transaction cost $[(\partial \bar{c} / \partial \eta)>0]$, which is consistent with the popular view that the recent decline in cash holdings is due to the advent of more convenient payment methods following the development of information technology.

From now on, we assume that $\bar{d}$ is given by $\bar{c}>0$, which minimizes the role of $\bar{d}$ in an unconstrained-price economy because a buyer with $m_{2} \leq \bar{c}$ will not be willing to make a deposit. $^{7}$ Then, the portfolios chosen by an agent with $m_{2}$ as a buyer $\left(\mathbf{a}_{m_{2}}^{b}\right)$ and as a seller $\left(\mathbf{a}_{m_{2}}^{s}\right)$ are given by

$$
\begin{aligned}
& \mathbf{a}_{m_{2}}^{b}= \begin{cases}\left(m_{2}, 0\right) & \text { if } m_{2} \leq \bar{c} \\
\left(\bar{c}, m_{2}-\bar{c}\right) & \text { otherwise, }\end{cases} \\
& \mathbf{a}_{m_{2}}^{s}= \begin{cases}\left(m_{2}, 0\right) & \text { if } m_{2} \leq \bar{c} \\
\left(0, m_{2}\right) & \text { otherwise. }\end{cases}
\end{aligned}
$$

The following lemma suggests that there would be no debit card trade if the transaction cost of debit cards is too large relative to the cash-holding cost.

Lemma 1 If $\eta<\varphi /(1+\varphi), q_{2, d}^{b}>0$ for an agent entering market 2 with $m_{2}>\bar{c}$.

\section{Proof. See Appendix A.}

Hereinafter, we will focus on the case of $\eta<\eta_{h} \equiv \varphi /(1+\varphi)$ because otherwise there would be no debit card transactions, which is not our interest at all. In this case, the marginal value of money in market 2 is given by

$$
V^{\prime}\left(m_{2}\right)=\left(\frac{\phi}{2}\right)\left\{\begin{array}{l}
{\left[\left(u^{\prime}\left(q_{2}^{b}\right)-\varphi\right) \mathbf{1}_{\left\{m_{2}<\bar{c}\right\}}+(1-\eta) u^{\prime}\left(q_{2}^{b}\right) \mathbf{1}_{\left\{\bar{c} \leq m_{2}<p_{2, d} \bar{q}_{2}\right\}}+\mathbf{1}_{\left\{m_{2} \geq p_{2, d} \bar{q}_{2}\right\}}\right]} \\
+\left[1-\varphi \mathbf{1}_{\left\{m_{2}<\bar{c}\right\}}\right]
\end{array}\right\}
$$

\footnotetext{
${ }^{7}$ As we will see, however, if there is no such requirement, no one is willing to hold cash in a constrainedprice economy.
} 
where $q_{2}^{b}=q_{2, c}^{b}+q_{2, d}^{b}$.

Finally, the lifetime utility of an agent entering market 1 with $m_{1} \in \mathbb{R}_{+}$is given by

$$
V_{1}\left(m_{1}\right)=\rho_{b}\left\{\max _{q_{1}^{b}}\left[u\left(q_{1}^{b}\right)+V_{2}\left(m_{1}-p_{1} q_{1}^{b}\right)\right]\right\}+\rho_{s}\left\{\max _{q_{1}^{s}}\left[V_{2}\left(m_{1}+p_{1} q_{1}^{s}\right)-q_{1}^{s}\right]\right\} .
$$

As in market 2, taking $p_{1}$ as given, a seller chooses $q_{1}^{s}$ which solves the second term on the right-hand side of (17). The first-order condition is

$$
\frac{1}{p_{1}}=V_{2}^{\prime}\left(m_{1}+p_{1} q_{1}^{s}\right)
$$

Similarly, taking $p_{1}$ as given, a buyer chooses $q_{1}^{b}$ which solves the first term on the right-hand side of (17) subject to $p_{1} q_{1}^{b} \leq m_{1}$. Notice that we can rule out the case of $p_{1} q_{1}^{b}=m_{1}$ because $u^{\prime}(0)=\infty$. The associated optimality condition is

$$
\frac{u^{\prime}\left(q_{1}^{b}\right)}{p_{1}}=V_{2}^{\prime}\left(m_{1}-p_{1} q_{1}^{b}\right)
$$

Noting that $p_{1} q_{1}^{b}=m_{1}$ is not binding in equilibrium, (18) and (19) immediately imply that

$$
V_{1}^{\prime}\left(m_{1}\right)=\frac{\rho_{b} u^{\prime}\left(q_{1}^{b}\right)+\rho_{s}}{p_{1}}
$$

Definition 1 A stationary and symmetric equilibrium in an unconstrained-price economy is $\left\{\left(p_{1}, p_{2, c}, p_{2, d}, p_{3}\right),\left[q_{1}^{b}\left(m_{1}\right), q_{1}^{s}, q_{2, c}^{b}\left(m_{2}\right), q_{2, d}^{b}\left(m_{2}\right), q_{2, c}^{s}, q_{2, d}^{s}, q_{3}\right],\left[V_{j}\left(m_{j}\right)\right]_{j=1}^{3},\left(\mathbf{a}_{m_{2}}^{b}, \mathbf{a}_{m_{2}}^{s}\right), m_{1,+1}\right\}$ which satisfies (1)-(9), (12)-(15), (17)-(19), and that clears each market $j \in\{1,2,3\}$.

\subsection{Constrained-Price Economy}

We now consider an economy employing a uniform pricing constraint for cash and debit card payments. Since the disparity between an unconstrained-price and a constrained-price economy emerges in market 2 only, we here focus on the behaviors within market 2 of a 
constrained-price economy.

Let $\breve{p}_{2}$ be the price of a good in market 2 and $\breve{q}_{2, c}\left(\breve{q}_{2, d}\right)$ be the quantity of good traded in market 2 via cash (debit cards) in a constrained-price economy. Since the price for debit card payments cannot be discriminated from that for cash payments, sellers finance the transaction cost of debit cards $\left(\eta \breve{p}_{2} \breve{q}_{2, d}^{s}\right)$ from all buyers whatever payment method they use. That is, taking $\breve{p}_{2}$ as given, a seller chooses $\breve{q}_{2}^{s}=\left(\breve{q}_{2, d}^{s}+\breve{q}_{2, c}^{s}\right)$ to maximize $\left\{-\breve{q}_{2}^{s}+V_{3}[c+d+\right.$ $\left.\left.\breve{p}_{2}(1-\breve{\eta}) \breve{q}_{2}^{s}\right]\right\}$, which yields the following maximization condition:

$$
\breve{p}_{2}=[(1-\breve{\eta}) \breve{\phi}]^{-1}
$$

where $\breve{\eta}$ is given by $\breve{\eta}=\eta\left(\breve{q}_{2, d}^{s} / \breve{q}_{2}^{s}\right)$. Similarly, the buyer chooses $\breve{q}_{2}^{b}$ to maximize $\left[u\left(\breve{q}_{2}^{b}\right)+\right.$ $\left.V_{3}\left(m_{2}-\breve{p}_{2} \breve{q}_{2}^{b}\right)\right]$ which gives the following optimality condition:

$$
u^{\prime}\left(\breve{q}_{2}^{b}\right)=\left(\breve{\phi}+\lambda_{m}\right) \breve{p}_{2}
$$

where $\lambda_{m}$ is the Lagrange multiplier on the buyer's wealth constraint $\left(\breve{p}_{2} \breve{q}_{2}^{b} \leq m_{2}\right)$. Using $(\breve{9}),(\breve{11})$ reduces to

$$
u^{\prime}\left(\breve{q}_{2}^{b}\right)=\frac{1}{(1-\breve{\eta})}\left(1+\frac{\lambda_{m}}{\breve{\phi}}\right)
$$

Let $\breve{q}_{2}^{u}$ be the solution to $(\breve{13})$ with $\lambda_{m}=0$.

The portfolio choice problem for this economy is relatively simple. That is, other than agents with $m_{2}<\bar{d}=\bar{c}$ where $\bar{c}$ is given by (14), all agents are willing to deposit money into checking accounts because the terms of trade for debit-card payments are the same as those for cash payments. Therefore, $\left(\breve{\mathbf{a}}_{m_{2}}^{b}, \breve{\mathbf{a}}_{m_{2}}^{s}\right)$ are given by

$$
\breve{\mathbf{a}}_{m_{2}}^{b}=\breve{\mathbf{a}}_{m_{2}}^{s}= \begin{cases}\left(m_{2}, 0\right) & \text { if } m_{2}<\bar{c} \\ \left(0, m_{2}\right) & \text { otherwise }\end{cases}
$$


Now the definition of a stationary equilibrium for a constrained-price economy is exactly symmetric to that for an unconstrained-price economy (i.e., Definition 1) with $p_{2, c}=p_{2, d}=\breve{p}_{2}$ and $q_{2, c}=q_{2, d}=\breve{q}_{2}$.

\section{Constrained or Unconstrained Price?}

In order to shed light on the question whether to impose a uniform pricing constraint for cash and debit card payments, we will compare economies with and without the constraint. In doing so, we first confine our attention to equilibria in which at the beginning of market 2 , the poor hold less money than the minimum requirement for opening an account, while the rich hold sufficient money to make the maximum possible trade, $\bar{q}_{2, c}$ in an unconstrainedprice economy and $\breve{q}_{2}^{u}$ in a constrained-price economy. We focus on these equilibria because as we will see below, their properties are somewhat consistent with empirical observations. Moreover, these equilibria imply that consumption in market 1 and that in market 3 are identical between an unconstrained-price and constrained-price economy. This conveniently allows us to concentrate on market 2 which contains the key ingredients associated with our main interest.

The following proposition shows that the equilibria we have an interest in exist if the transaction cost of a debit card is neither too large nor too small, agents are patient enough, and the fraction of buyers in market 1 is not too small.

Proposition 1 Suppose $\eta \in\left(\eta_{l}, \eta_{h}\right), \beta \in\left[\beta_{l}, 1\right)$ and $\rho_{b} \in\left[\rho_{l}, 1\right)$ where $\left(\eta_{l}, \beta_{l}, \rho_{l}\right)$ are defined in Appendix A.

1. In an unconstrained-price economy, (i) there is an equilibrium with $m_{1,+1}-p_{1} q_{1}^{b}<\bar{c}$ and $m_{1,+1}+p_{1} q_{1}^{s} \geq p_{2, d} \bar{q}_{2, c}$, and (ii) in market 2 of this equilibrium, a rich buyer uses both cash and a debit card, whereas a poor buyer uses cash only. 
2. In a constrained-price economy, (i) there is an equilibrium with $m_{1,+1}-\breve{p}_{1} \breve{q}_{1}^{b}<\bar{c}$ and $m_{1,+1}+\breve{p}_{1} \breve{q}_{1}^{s} \geq \breve{p}_{2} \breve{q}_{2}^{u}$, and (ii) in market 2 of this equilibrium, a rich buyer uses a debit card only, whereas a poor buyer uses cash only.

\section{Proof. See Appendix A.}

Intuitively, if the transaction cost of a debit card $(\eta)$ is too large, as shown in Lemma 1, even rich buyers are not willing to make debit card transactions. On the other hand, cash trades will disappear if $\eta \rightarrow 0$ because $\bar{c}$ converges to zero from (14). If the discount factor $(\beta)$ is too low, agents are not willing to accumulate large real balances, which lowers the value of money. The real balance of money held by the rich in market 2 would then not be enough to make the maximum possible trade, $\bar{q}_{2, c}$ or $\breve{q}_{2}^{u}$. Similarly, if $\rho_{b}$ is too low, a seller in market 1 cannot make sufficient money and hence her real balance in market 2 would not be large enough to complete the transaction of $\bar{q}_{2, c}$ or $\breve{q}_{2}^{u}$.

\subsection{Welfare}

As a criterion for making the comparison between an unconstrained-price and a constrainedprice economy, we adopt welfare defined as the lifetime expected discounted utility of a representative agent at the beginning of the period. Let $\mathbb{W}$ and $\breve{W}$ denote the welfare for an unconstrained-price and a constrained-price equilibrium respectively. Then $\mathbb{W}$ is given by

$$
\mathbb{W}(1-\beta)=\left[\rho_{b} u\left(q_{1}^{b}\right)-\rho_{s} q_{1}^{s}\right]+\left[\mathbb{E}\left(\boldsymbol{U}_{2}\right)-\mathbb{E}(\boldsymbol{C})\right]+\left[U\left(q_{3}\right)-q_{3}\right]
$$

where $\mathbb{E}\left(\boldsymbol{U}_{2}\right)$ and $\mathbb{E}(\boldsymbol{C})$ denote the expected utility gain from trades in market 2 and the expected cash-holding cost respectively. With $q_{2}^{r}$ and $q_{2}^{p}$ denoting the consumption of a rich buyer and a poor buyer respectively in an unconstrained-price equilibrium, $\mathbb{E}\left(\boldsymbol{U}_{2}\right)$ can be expressed as

$$
\mathbb{E}\left(\boldsymbol{U}_{2}\right)=\left(\frac{1}{2}\right)\left[\rho_{s} u\left(q_{2}^{r}\right)+\rho_{b} u\left(q_{2}^{p}\right)-\bar{q}_{2}^{s}\right]
$$


where $\bar{q}_{2}^{s}=\left(\rho_{s} q_{2}^{r}+\rho_{b} q_{2}^{p}\right)$ by market-2 clearing condition. In regard to $\mathbb{E}(\boldsymbol{C})$, notice that all agents enter market 1 with an identical amount of money, $M$. Then a fraction of agents $\rho_{b}$ spend some of it as buyers in market 1 and hence they are poor at the beginning of market 2, while a fraction of agents $\rho_{s}$ make some money as sellers in market 1 and hence they are rich. Then from (15), a fraction of agents $\rho_{b}$ hold all their money in the form of cash in market 2, whereas half of the fraction of agents $\rho_{s}$ hold $\bar{c}$ amount of cash as a buyer and the remaining half do not hold cash because they are sellers. Hence $\mathbb{E}(\boldsymbol{C})$ can be expressed as

$$
\mathbb{E}(\boldsymbol{C})=\varphi\left[\rho_{b}\left(M-p_{1} q_{1}^{b}\right) \phi+\frac{\rho_{s}}{2} \bar{c} \phi\right]
$$

Similarly, $\breve{\mathbb{W}}$ is given by

$$
\breve{\mathbb{W}}(1-\beta)=\left[\rho_{b} u\left(\breve{q}_{1}^{b}\right)-\rho_{s} \breve{q}_{1}^{s}\right]+\left[\mathbb{E}\left(\breve{\boldsymbol{U}}_{2}\right)-\mathbb{E}(\breve{\boldsymbol{C}})\right]+\left[U\left(\breve{q}_{3}\right)-\breve{q}_{3}\right]
$$

With $\breve{q}_{2}^{r}$ and $\breve{q}_{2}^{p}$ denoting respectively the consumption of a rich buyer and a poor buyer in a constrained-price equilibrium, $\mathbb{E}\left(\breve{\boldsymbol{U}}_{2}\right)$ can be expressed as

$$
\mathbb{E}\left(\breve{\boldsymbol{U}}_{2}\right)=\left(\frac{1}{2}\right)\left[\rho_{s} u\left(\breve{q}_{2}^{r}\right)+\rho_{b} u\left(\breve{q}_{2}^{p}\right)-\breve{q}_{2}^{s}\right]
$$

where $\breve{q}_{2}^{s}=\left(\rho_{s} \breve{q}_{2}^{r}+\rho_{b} \breve{q}_{2}^{p}\right)$. In regard to $\mathbb{E}(\breve{\boldsymbol{C}})$, from ( $\left.\breve{15}\right)$, only the fraction of agents $\rho_{b}$ hold cash and hence,

$$
\mathbb{E}(\breve{\boldsymbol{C}})=\varphi\left[\rho_{b}\left(M-\breve{p}_{1} \breve{q}_{1}^{b}\right) \breve{\phi}\right]
$$

Since $u^{\prime}\left(q_{1}^{b}\right)=u^{\prime}\left(\breve{q}_{1}^{b}\right)=\left[\left(1-\beta+\beta \rho_{b}\right) / \beta \rho_{b}\right]$ and $q_{3}=\breve{q}_{3}=q_{3}^{*}=\arg \max \left[U\left(q_{3}^{b}\right)-q_{3}^{b}\right]($ see Appendix A for the proof of Proposition 1), the welfare difference between a constrained-price and an unconstrained-price equilibrium can be simplified as

$$
\Delta \breve{\mathbb{W}} \equiv(\breve{\mathbb{W}}-\mathbb{W})=[\Delta \breve{U}+\Delta \breve{\mathbb{C}}]
$$


where $\Delta \breve{\mathbb{U}}=\left[\mathbb{E}\left(\breve{\boldsymbol{U}}_{2}\right)-\mathbb{E}\left(\boldsymbol{U}_{2}\right)\right] /(1-\beta)$ and $\Delta \breve{\mathbb{C}}=[\mathbb{E}(\boldsymbol{C})-\mathbb{E}(\breve{\boldsymbol{C}})] /(1-\beta)$. Then obviously, the benevolent government can enhance welfare by imposing a uniform pricing constraint for cash and debit card payments if $\Delta \breve{U}+\Delta \breve{C}>0$.

\subsection{Cash-Holding Cost}

In order to determine the sign of $\Delta \breve{\mathbb{W}}=\Delta \breve{U}+\Delta \breve{\mathbb{C}}$, we first discuss the difference in the cash-holding cost, $\Delta \breve{\mathbb{C}}$. The following proposition suggests that the cash-holding cost in an unconstrained-price equilibrium is higher than in a constrained-price equilibrium.

Proposition $2 \Delta \breve{\mathbb{C}}=[\mathbb{E}(\boldsymbol{C})-\mathbb{E}(\breve{C})](1-\beta)^{-1}>0$ in an equilibrium of Proposition 1 .

\section{Proof. See Appendix A.}

The intuition for the result above is straightforward. Since the terms of trade for cash payments are more favorable than those for debit card payments in an unconstrained-price economy, agents in an unconstrained-price economy are willing to hold more cash than in a constrained-price economy. Proposition 2 also implies that the proportion of debit card transactions in a constrained-price equilibrium would be higher than that in an unconstrainedprice equilibrium, which is consistent with the empirical observation of Bolt, Jonker and van Renselaar (2010).

Proposition 3 Compared to an unconstrained-price equilibrium, a constrained-price equilibrium implies that the quantity of good traded by debit cards is relatively large, whereas the quantity of good traded by cash is relatively small.

\section{Proof. See Appendix A.}

This result corresponds with the "Gresham's Law of Payments" due to Macfarlane (2005) in the sense that the more costly payment method (debit card) drives out the less costly payment method (cash). 


\subsection{Utility Gain from Consumption}

We now move on to the difference in the expected utility gain from the trades in market 2, $\Delta \breve{U}=\left[\mathbb{E}\left(\breve{\boldsymbol{U}}_{2}\right)-\mathbb{E}\left(\boldsymbol{U}_{2}\right)\right] /(1-\beta)$. Notice that the poor in market 2 would be better off in an unconstrained-price equilibrium, whereas the rich in market 2 would be better off in a constrained-price equilibrium. Under a uniform pricing constraint, the transaction cost of debit cards is shared by cash users, and hence the burden for debit-card users is alleviated, whereas the burden for cash users is aggravated. This conforms to the results in Carlton and Frankel (1995), Schwartz and Vincent (2006), and Schuh, Shy and Stavins (2010).

Proposition 4 Compared to an unconstrained-price equilibrium, a constrained-price equilibrium implies that market-2 consumption by the rich is relatively large, whereas that by the poor is relatively small.

\section{Proof. See Appendix A.}

Proposition 4 suggests that the dispersion in market-2 consumption between the rich and the poor in a constrained-price equilibrium is higher than in an unconstrained-price equilibrium, $\left(q_{2}^{r}-q_{2}^{p}\right)<\left(\breve{q}_{2}^{r}-\breve{q}_{2}^{p}\right)$. This, together with $u^{\prime \prime}<0$, implies that $\Delta \breve{\mathbb{U}}=\left[\mathbb{E}\left(\breve{U}_{2}\right)-\right.$ $\left.\mathbb{E}\left(\boldsymbol{U}_{2}\right)\right] /(1-\beta)$ would be negative if $\rho_{b}$ is not too small.

\subsection{Welfare Comparison}

Proposition 2 and 4 imply that the welfare ranking between a constrained-price and an unconstrained-price economy is ambiguous because $\Delta \breve{U}<0$ and $\Delta \breve{\mathbb{C}}>0$. In other words, the sign of $\Delta \breve{\mathbb{W}}=(\breve{\mathbb{W}}-\mathbb{W})=\Delta \breve{U}+\Delta \breve{\mathbb{C}}$ relies on the relative magnitude of the cost-saving effect of cash holdings in a constrained-price economy and the consumption-smoothing effect in an unconstrained-price economy. We illustrate these two effects using numerical examples.

Our parameterization for the background model is as follows. We let $\beta=0.99$ and $u(q)=q^{1-\sigma} /(1-\sigma)$ with $\sigma=\{1 / 2,1,2\}$ where $\sigma=1$ is understood to be the log case. We 
then consider a wider range of $\eta$ such as $\eta \in\{0.001,0.003,0.006\} .{ }^{8}$ For a given $\eta$, Lemma 1 implies that $\varphi>[\eta /(1-\eta)]$ for the existence of debit card transactions. Considering this condition, we set $\varphi=[\eta /(1-\eta)] \times 1.001$ for each $\eta$ to minimize the effect of $\varphi$ on welfare.

Table 1 reports consumption equivalent welfare loss in an unconstrained-price economy relative to a constrained-price economy where the welfare loss $(\omega)$ is calculated by solving

$$
\Delta \breve{\mathbb{C}}[2(1-\beta)]=\left\{\rho_{s} u\left[q_{2}^{r}(1+\omega)\right]+\rho_{b} u\left[q_{2}^{p}(1+\omega)\right]-\bar{q}_{2}^{s}\right\}-\left[\rho_{s} u\left(\breve{q}_{2}^{r}\right)+\rho_{b} u\left(\breve{q}_{2}^{p}\right)-\breve{q}_{2}^{s}\right]
$$

Our examples show that the cost-saving effect of cash holdings in a constrained-price economy dominates the consumption-smoothing effect in an unconstrained-price economy. In particular, depending on $\left(\eta, \rho_{s}, \sigma\right)$, welfare gain in a constrained-price economy mounts up to around $0.4 \%$ of the consumption in market 2 of an unconstrained-price economy. ${ }^{9}$

As a robustness check, we change the cost function of cash holdings from $C=\varphi z$ to $\boldsymbol{C}=\varphi \sqrt{z}$ where $z$ denotes the real balance of cash holdings. Table 2 shows that an altered cost function does not qualitatively change our result $(\Delta \breve{W}>0)$. This is also the case with $\boldsymbol{C}=\varphi z^{2}$, although we do not report the results here to save space.

One might suggest that we could find a counterexample in which $\Delta \breve{W}<0$ by scaling $\varphi$ to be sufficiently small. However, it will eventually violate the condition in Lemma 1 , $\varphi>[\eta /(1-\eta)]$, and hence the existence of equilibria in Proposition 1 cannot be ensured. It is also worthwhile to note that our model essentially captures the lower bound of the cost-saving effect of cash holdings in the sense that if there is no minimum requirement for opening an account, no one is willing to hold cash in a constrained-price economy and so $\mathbb{E}(\breve{\boldsymbol{C}})=0$. However, $\mathbb{E}(\boldsymbol{C})$ in $(22)$ is irrelevant to the minimum requirement for opening an

\footnotetext{
${ }^{8}$ Regulation II is estimated to lower the average cost of debit card transaction from $1.17 \%$ to around $0.6 \%$ (see Shy 2012).

${ }^{9}$ For more details on the numerical results, see Appendix B. As shown in the previous subsections, regardless of $(\eta, \sigma)$ considered, $q_{2}^{r}<\breve{q}_{2}^{r}$ and $q_{2}^{p}>\breve{q}_{2}^{p}$ due to the cost-sharing effect in a constrained-price economy, $\mathbb{E}\left(\breve{\boldsymbol{U}}_{2}\right)<\mathbb{E}\left(\boldsymbol{U}_{2}\right)$ due to the consumption-smoothing effect in an unconstrained-price economy, and $\mathbb{E}(\boldsymbol{C})>\mathbb{E}(\breve{C})$ due to the cost-saving effect of cash holdings in a constrained-price economy.
} 
Table 1: Welfare loss (\%) of an unconstrained-price economy

\begin{tabular}{|c|c|c|c|c|c|c|c|c|}
\hline \multicolumn{9}{|c|}{$\eta=0.001$} \\
\hline \multicolumn{3}{|c|}{$\rho_{s}=0.3$} & \multicolumn{3}{|c|}{$\rho_{s}=0.5$} & \multicolumn{3}{|c|}{$\rho_{s}=0.7$} \\
\hline$\sigma=1 / 2$ & $\sigma=1$ & $\sigma=2$ & $\sigma=1 / 2$ & $\sigma=1$ & $\sigma=2$ & $\sigma=1 / 2$ & $\sigma=1$ & $\sigma=2$ \\
\hline 0.0294 & 0.0294 & 0.0298 & 0.0491 & 0.0490 & 0.0498 & 0.0688 & 0.0687 & 0.0697 \\
\hline \multicolumn{9}{|c|}{$\eta=0.003$} \\
\hline \multicolumn{3}{|c|}{$\rho_{s}=0.3$} & \multicolumn{3}{|c|}{$\rho_{s}=0.5$} & \multicolumn{3}{|c|}{$\rho_{s}=0.7$} \\
\hline$\sigma=1 / 2$ & $\sigma=1$ & $\sigma=2$ & $\sigma=1 / 2$ & $\sigma=1$ & $\sigma=2$ & $\sigma=1 / 2$ & $\sigma=1$ & $\sigma=2$ \\
\hline 0.0885 & 0.0883 & 0.0882 & 0.1475 & 0.1473 & 0.1472 & 0.2067 & 0.2063 & 0.2063 \\
\hline \multicolumn{9}{|c|}{$\eta=0.006$} \\
\hline \multicolumn{3}{|c|}{$\rho_{s}=0.3$} & \multicolumn{3}{|c|}{$\rho_{s}=0.5$} & \multicolumn{3}{|c|}{$\rho_{s}=0.7$} \\
\hline$\sigma=1 / 2$ & $\sigma=1$ & $\sigma=2$ & $\sigma=1 / 2$ & $\sigma=1$ & $\sigma=2$ & $\sigma=1 / 2$ & $\sigma=1$ & $\sigma=2$ \\
\hline 0.1779 & 0.1769 & 0.1766 & 0.2960 & 0.2950 & 0.2948 & 0.4142 & 0.4132 & 0.4133 \\
\hline
\end{tabular}

account because every buyer in an unconstrained-price economy is willing to hold cash up to $\bar{c}$.

Finally, once the government imposes a uniform-price constraint, a policy that lowers the transaction cost of debit cards such as Regulation II would improve welfare. Noting $u^{\prime}\left(\breve{q}_{2}^{r}\right)=[1 /(1-\breve{\eta})]$ from $(\breve{13}), \breve{q}_{2}^{r}$ increases as $\eta$ declines because it implies a lower $\breve{\eta}$. In addition, $\breve{q}_{2}^{p}=\breve{\phi}\left(M-\breve{p}_{1} \breve{q}_{1}^{b}\right)$ where $\breve{\phi} \breve{p}_{1}=1$ and $\breve{q}_{1}^{b}$ is irrelevant to $\eta$ (see Appendix A for the proof of Proposition 1). Then as $\eta$ declines, $\breve{q}_{2}^{p}$ also increases because $\breve{\phi} M$ rises (see (28) in Appendix A). Therefore, the consumption for both the poor and the rich in market 2 is boosted by lowing $\eta$ which eventually enhances welfare. 
Table 2: Welfare loss (\%) of an unconstrained-price economy with $\boldsymbol{C}=\varphi \sqrt{z}$

\begin{tabular}{|c|c|c|c|c|c|c|c|}
\hline \multicolumn{8}{|c|}{$\eta=0.001$} \\
\hline \multicolumn{3}{|c|}{$\rho_{s}=0.3$} & \multicolumn{3}{|c|}{$\rho_{s}=0.5$} & \multicolumn{2}{|l|}{$\rho_{s}=0.7$} \\
\hline$\sigma=1 / 2$ & $\sigma=1$ & $\sigma=2$ & $\sigma=1 / 2$ & $\sigma=1$ & $\sigma=2$ & $\sigma=1 / 2 \quad \sigma=1$ & $\sigma=2$ \\
\hline 0.0295 & 0.0294 & 0.0294 & 0.0491 & 0.0490 & 0.0491 & $0.0689 \quad 0.0687$ & 0.0687 \\
\hline \multicolumn{8}{|c|}{$\eta=0.003$} \\
\hline \multicolumn{3}{|c|}{$\rho_{s}=0.3$} & \multicolumn{3}{|c|}{$\rho_{s}=0.5$} & \multicolumn{2}{|l|}{$\rho_{s}=0.7$} \\
\hline$\sigma=1 / 2$ & $\sigma=1$ & $\sigma=2$ & $\sigma=1 / 2$ & $\sigma=1$ & $\sigma=2$ & $\sigma=1 / 2 \quad \sigma=1$ & $\sigma=2$ \\
\hline 0.0948 & 0.0883 & 0.0898 & 0.1575 & 0.1473 & 0.1483 & $0.2196 \quad 0.2065$ & 0.2098 \\
\hline \multicolumn{8}{|c|}{$\eta=0.006$} \\
\hline \multicolumn{3}{|c|}{$\rho_{s}=0.3$} & \multicolumn{3}{|c|}{$\rho_{s}=0.5$} & \multicolumn{2}{|l|}{$\rho_{s}=0.7$} \\
\hline$\sigma=1 / 2$ & $\sigma=1$ & $\sigma=2$ & $\sigma=1 / 2$ & $\sigma=1$ & $\sigma=2$ & $\sigma=1 / 2 \quad \sigma=1$ & $\sigma=2$ \\
\hline 0.1777 & 0.1768 & 0.1766 & 0.2965 & 0.2952 & 0.2950 & 0.4160 & 0.4139 \\
\hline
\end{tabular}

\section{Concluding Remarks}

This paper compares the welfare of a constrained-price economy to that of an unconstrainedprice economy using a standard monetary model. Our analytical results suggest that a constrained-price economy is superior to an unconstrained-price economy from the standpoint of the cash-holding cost but the reverse is true from the standpoint of consumption smoothing. Our numerical examples support a uniform pricing constraint for cash and debit card payments.

It is worth noting that in order to concentrate our analysis on the features of payment methods, we do not take into account the issues facing payment-service providers. To study this problem in the context of microfounded monetary models, we could consider the competitive-price-posting model in Rocheteau and Wright (2005) and Faig and Huangfu 
(2007). As a market maker, a profit-maximizing payment-service provider can open a submarket where she posts terms of trade and entry fees that can vary across buyers and sellers.

We can also take a model in which inflation is introduced. Monnet and Roberds (2008) argue for a no-surcharge rule for credit card payments in a low-inflation economy. A nosurcharge rule ensures that the credit card system is viable when inflation is low, which then enhances welfare by relaxing the cash constraints on potential buyers. We conjecture that a no-surcharge rule for debit card payments would still hold in our model with inflation because inflation will add to the cost of using cash.

\section{Appendix A: Proofs}

Proof of Lemma 1: Notice first that after the realization of the idiosyncratic trading shock for market 2 , an agent as a buyer with $m_{2}>\bar{c}$ chooses a portfolio $(c, d)=\left(\bar{c}, m_{2}-\bar{c}\right)$. If $\bar{c} \geq p_{2, c} \bar{q}_{2}, q_{2, d}^{b}=0$ from (12) and (13). Hence, to have a debit card transaction, $\bar{c}$ should be less than $p_{2, c} \bar{q}_{2}$. Then $u^{\prime}\left(\bar{c} / p_{2, c}\right)>u^{\prime}\left(\bar{q}_{2}\right)=(1-\eta)^{-1}$, which can be rewritten as $(\varphi / \eta)>(1-\eta)^{-1}$ because $u^{\prime}\left(\bar{c} / p_{2, c}\right)=\varphi / \eta$ from (14). Therefore, as a buyer in market 2 , an agent with $m_{2}>\bar{c}$ makes a debit-card transaction if $\eta<[\varphi /(1+\varphi)]$.

Proof of Proposition 1: 1-(i). We need to show that there is an equilibrium with $M-$ $p_{1} q_{1}^{b}<\bar{c}$ and $M+p q_{1}^{b} \rho_{b} \rho_{s}^{-1} \geq p_{2, d} \bar{q}_{2, c}$ where we use the money-market clearing condition $\left(m_{1,+1}=M\right)$ and market-1 clearing condition $\left(\rho_{s} q_{1}^{s}=\rho_{b} q_{1}^{b}\right)$. An agent entering market 2 with $M-p_{1} q_{1}^{b}<\bar{c}$ chooses a portfolio $\left(M-p_{1} q_{1}^{b}, 0\right)$ due to a minimum requirement for opening an account, whereas an agent with $M+p_{1} q_{1}^{b} \rho_{b} \rho_{s}^{-1} \geq p_{2, d} \bar{q}_{2, c}$ chooses a portfolio $\left(0, M+p_{1} q_{1}^{b} \rho_{b} \rho_{s}^{-1}\right)$ as a seller and $\left(\bar{c}, M+p_{1} q_{1}^{b} \rho_{b} \rho_{s}^{-1}-\bar{c}\right)$ as a buyer because $\bar{c}<p_{2, d} \bar{q}_{2, c}$ from Lemma 1. Then, $V_{2}^{\prime}\left(M+p_{1} q_{1}^{b} \rho_{b} \rho_{s}^{-1}\right)=\phi$ from (16) which together with (18) implies that $\left(1 / p_{1}\right)=\phi$. Also, (3) and $(20)$ give $u^{\prime}\left(q_{1}^{b}\right)=\left[\left(1-\beta+\beta \rho_{b}\right) / \beta \rho_{b}\right]$ that determines $q_{1}^{b}(M)$ such that $q_{1}^{b}(M)<q^{*}=\arg \max [u(q)-q]$ and then $q_{1}^{s}=q_{1}^{b} \rho_{b} \rho_{s}^{-1}$. Since $V_{2}^{\prime}\left(M-p_{1} q_{1}^{b}\right)=$ 
$\phi\left[(1 / 2) u^{\prime}\left(\Phi-\phi p_{1} q_{1}^{b}\right)+(1 / 2)-\varphi\right]$ from (16), we further have

$$
u^{\prime}\left(q_{1}^{b}\right)=\left[\frac{u^{\prime}\left(\Phi-q_{1}^{b}\right)+1}{2}\right]-\varphi
$$

from (19), which determines $\Phi=\phi M$ for a given $q_{1}^{b}(M)$, and then $\left(p_{2, c}, p_{2, d}\right)$ from (8) and (9) respectively. In addition, $q_{2, c}^{b}\left(M-p_{1} q_{1}^{b}\right)=\Phi-q_{1}^{b}(M), q_{2, c}^{b}\left(M+p q_{1}^{b} \rho_{b} \rho_{s}^{-1}\right)=\hat{q}_{2, c}=\phi \bar{c}, q_{2, c}^{s}=$ $\rho_{s} \hat{q}_{2, c}+\rho_{b}\left[\Phi-q_{1}^{b}(M)\right], q_{2, d}^{b}\left(M-p_{1} q_{1}^{b}\right)=0, q_{2, d}^{b}\left(M+p q_{1}^{b} \rho_{b} \rho_{s}^{-1}\right)=\bar{q}_{2}-\hat{q}_{2, c}, q_{2, d}^{s}=\rho_{s}\left(\bar{q}_{2}-\hat{q}_{2, c}\right)$, and $q_{3}=q_{3}^{*}=\arg \max \left[U\left(q_{3}^{b}\right)-q_{3}^{b}\right]$. Finally, in order for this equilibrium to exist, the real balances for the rich and for the poor in market 2 should satisfy $(1-\eta) \Phi+(1-\eta) q_{1}^{b} \rho_{b} \rho_{s}^{-1} \geq \bar{q}_{2, c}$ and $(1-\eta) \Phi-(1-\eta) q_{1}^{b}<(1-\eta) \phi \bar{c}$, respectively: i.e., the sufficient condition for this equilibrium is $\bar{q}_{2, c}-(1-\eta) q_{1}^{b} \rho_{b} \rho_{s}^{-1} \leq(1-\eta) \Phi<(1-\eta)\left(\phi \bar{c}+q_{1}^{b}\right)$. If $\eta \rightarrow \varphi /(1+\varphi) \equiv \eta_{h}$ and $\beta \rightarrow 1$, $u^{\prime}\left(q_{1}^{b}\right)=1=u^{\prime}\left(\bar{q}_{2, c}\right)$ and hence $\bar{q}_{2, c}-(1-\eta) q_{1}^{b} \rho_{b} \rho_{s}^{-1}=\left[1-(1-\eta) \rho_{b} \rho_{s}^{-1}\right] q_{1}^{b} \leq[1-(\varphi /(1+\varphi))] q_{1}^{b}$ where the last inequality holds if $\rho_{b} \geq \varphi \rho_{s}=\varphi\left(1-\rho_{b}\right)$. That is, if $\rho_{b} \geq \varphi /(1+\varphi) \equiv \rho_{l}$, then $\bar{q}_{2, c}-(1-\eta) q_{1}^{b} \rho_{b} \rho_{s}^{-1} \leq[1 /(1+\varphi)] q_{1}^{b} \leq(1-\eta) \Phi=[1 /(1+\varphi)] \Phi$ because $\varphi<1$ and $\Phi \geq q_{1}^{b}$. In addition, $\Phi-q_{1}^{b}<\phi \bar{c}$ because $u^{\prime}\left(\Phi-q_{1}^{b}\right)=1+2 \varphi$ from $(27)$ and $u^{\prime}(\phi \bar{c})=1+\varphi$ from (14). Therefore, the sufficient condition holds. Now suppose $\beta$ decreases from 1 . Notice that $\left(\partial q_{1}^{b} / \partial \beta\right)=(-1) /\left[u^{\prime \prime}\left(q_{1}^{b}\right) \beta^{2} \rho_{b}\right]>0,(\partial \Phi / \partial \beta)=\left[\left(\partial q_{1}^{b} / \partial \beta\right)\left(\partial \Phi / \partial q_{1}^{b}\right)\right]=\left(\partial q_{1}^{b} / \partial \beta\right)\left[u^{\prime \prime}\left(q_{1}^{b}\right)+\right.$ $\left.u^{\prime \prime}\left(\Phi-q_{1}^{b}\right)\right] / u^{\prime \prime}\left(\Phi-q_{1}^{b}\right),\left|\partial q_{1}^{b} / \partial \beta\right|<|\partial \Phi / \partial \beta|$, and $\left(\bar{q}_{2, c}, \phi \bar{c}\right)$ do not rely on $\beta$. Hence the right-hand inequality of the sufficient condition is preserved. However, for a low enough $\beta$, say $\beta_{l}$, the left-hand inequality will bind and beyond that will be violated. Now suppose $\eta$ decreases from $\eta_{h}$. Notice that from (14), $\phi \bar{c}$ declines as $\eta$ decreases but $\left(\Phi, q_{1}^{b}, \bar{q}_{2, c}\right)$ do not rely on $\eta$. Hence the left-hand inequality of the sufficient condition is preserved. However, since $\phi \bar{c} \rightarrow 0$ as $\eta \rightarrow 0$, the right-hand inequality will be violated at $\eta=0$. This implies that for some $\eta \in\left(0, \eta_{h}\right)$, say $\eta_{l}, \Phi=\left(\phi \bar{c}+q_{1}^{b}\right)$. Therefore, this equilibrium exists for $\eta \in\left(\eta_{l}, \eta_{h}\right)$, $\beta \in\left[\beta_{l}, 1\right)$ and $\rho_{b} \in\left[\rho_{l}, 1\right)$.

1-(ii). The results are obvious consequences that at the beginning of market 2, a rich buyer holds $M+p_{1} q_{1}^{b} \rho_{b} \rho_{s}^{-1} \geq p_{2, d} \bar{q}_{2, c}$ and a poor buyer holds $M-p_{1} q_{1}^{b}<\bar{c}$. 
2-(i). Since there is an equilibrium with $M-p_{1} q_{1}^{b}<\bar{c}$ and $M+p_{1} q_{1}^{b} \rho_{b} \rho_{s}^{-1} \geq p_{2, d} \bar{q}_{2, c}$ for $\eta \in\left(\eta_{l}, \eta_{h}\right), \beta \in\left[\beta_{l}, 1\right)$ and $\rho_{b} \in\left[\rho_{l}, 1\right)$, there is also an equilibrium with $M-\breve{p}_{1} \breve{q}_{1}^{b}<\bar{c}$ and $M+\breve{p}_{1} \breve{q}_{1}^{b} \rho_{b} \rho_{s}^{-1} \geq \breve{p}_{2} \breve{q}_{2}^{u}$ if $\breve{p}_{2} \leq p_{2, d}, \breve{p}_{1} \geq p_{1}, \breve{q}_{1}^{b} \geq q_{1}^{b}$, and $\bar{q}_{2, c} \geq \breve{q}_{2}^{u}$. Notice that an agent entering market 2 with $M-\breve{p}_{1} \breve{q}_{1}^{b}<\bar{c}$ chooses a portfolio $\left(M-\breve{p}_{1} \breve{q}_{1}^{b}, 0\right)$ due to a minimum requirement for opening an account, whereas an agent with $M+\breve{p}_{1} \breve{q}_{1}^{b} \rho_{b} \rho_{s}^{-1} \geq \breve{p}_{2} \breve{q}_{2}^{u}$ chooses a portfolio $\left(0, M+\breve{p}_{1} \breve{q}_{1}^{b} \rho_{b} \rho_{s}^{-1}\right)$ due to $\bar{c}<\breve{p}_{2} \breve{q}_{2}^{u}$ from Lemma 1. Then, $V_{2}^{\prime}\left(M+\breve{p}_{1} \breve{q}_{1}^{b} \rho_{b} \rho_{s}^{-1}\right)=\breve{\phi}$ from (16) which together with (18) implies that $\left(1 / \breve{p}_{1}\right)=\breve{\phi}$. Also, (3) and (20) gives $u^{\prime}\left(\breve{q}_{1}^{b}\right)=\left[\left(1-\beta+\beta \rho_{b}\right) / \beta \rho_{b}\right]$ that implies $\breve{q}_{1}^{b}(M)=q_{1}^{b}(M)$. In addition, since $V_{2}^{\prime}\left(M-\breve{p}_{1} \breve{q}_{1}^{b}\right)=$ $\breve{\phi}\left[(1 / 2)(1-\breve{\eta}) u^{\prime}\left(\breve{\Phi}-\breve{\phi} \breve{p}_{1} \breve{q}_{1}^{b}\right)+(1 / 2)-\varphi\right]$ from (16), we further have

$$
u^{\prime}\left(\breve{q}_{1}^{b}\right)=\left[\frac{(1-\breve{\eta}) u^{\prime}\left(\breve{\Phi}-\breve{q}_{1}^{b}\right)+1}{2}\right]-\varphi
$$

from (19), which determines $\breve{\Phi}=\breve{\phi} M$ for a given $\breve{q}_{1}^{b}(M)$ and then $\breve{p}_{2}$ from $(\breve{9})$. Notice that since $\breve{q}_{1}^{b}(M)=q_{1}^{b}(M)$ and $\breve{\eta}>0, \breve{\Phi}<\Phi$ and hence $\breve{\phi}<\phi$. Since $\breve{\phi}<\phi, p_{2, c}=$ $p_{1}=(1 / \phi)<\breve{p}_{2}=\breve{p}_{1}=(1 / \breve{\phi})<p_{2, d}$ where the last inequality is due to $p_{2, d}=(1 / \breve{\phi})$ with $\breve{\phi}$ satisfying $u^{\prime}\left(\breve{q}_{1}^{b}\right)=\left[(1 / 2)(1-\eta) u^{\prime}\left(\breve{\Phi}-\breve{q}_{1}^{b}\right)+(1 / 2)-\varphi\right]$. In addition, $\bar{q}_{2}<\breve{q}_{2}^{u}<\bar{q}_{2, c}$

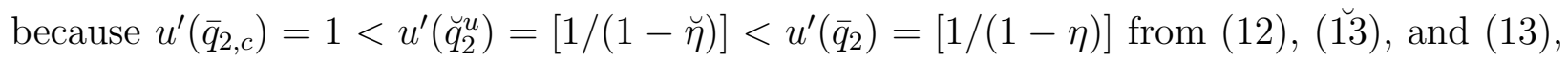
respectively, which completes the proof.

2-(ii). Exactly the same argument in 1-(ii) can be applied here.

Proof of Proposition 2: By substituting $p_{1}=1 / \phi$ and $\breve{p}_{1}=1 / \breve{\phi}$ from the proof of Proposition 1, we have

$$
\Delta \breve{\mathbb{C}}=\varphi\left[\rho_{b}(\Phi-\breve{\Phi})+\frac{\rho_{s} \bar{c} \phi}{2}\right]\left(\frac{1}{1-\beta}\right)
$$

which immediately implies the result because $\Phi>\breve{\Phi}$ as shown above.

Proof of Proposition 3: In a constrained-price equilibrium, the quantity of good traded 
by debit cards is $\left(\rho_{s} / 2\right) \breve{q}_{2}^{u}$ and that traded by cash is $\left(\rho_{b} / 2\right)\left(\breve{\Phi}-\breve{q}_{1}^{b}\right)$. Meanwhile, in an unconstrained-price equilibrium, the quantity of good traded by debit cards is $\left(\rho_{s} / 2\right)\left(\bar{q}_{2}-\right.$ $\left.\hat{q}_{2, c}\right)=\left(\rho_{s} / 2\right)\left(\bar{q}_{2}-\phi \bar{c}\right)$ and that traded by cash is $\left(\rho_{b} / 2\right)\left(\Phi-q_{1}^{b}\right)$. Since $u^{\prime}\left(\breve{q}_{2}^{u}\right)=[1 /(1-\breve{\eta})]<$ $[1 /(1-\eta)]=u^{\prime}\left(\bar{q}_{2}\right),\left(\rho_{s} / 2\right) \breve{q}_{2}^{u}>\left(\rho_{s} / 2\right)\left(\bar{q}_{2}-\phi \bar{c}\right)$. In addition, since $\breve{\Phi}<\Phi$ and $q_{1}^{b}=\breve{q}_{1}^{b}$, $\left(\rho_{b} / 2\right)\left(\Phi-q_{1}^{b}\right)>\left(\rho_{b} / 2\right)\left(\breve{\Phi}-\breve{q}_{1}^{b}\right)$.

Proof of Proposition 4: Notice that $\left(q_{2}^{r}, q_{2}^{p}\right)=\left(\bar{q}_{2}, \Phi-q_{1}^{b}\right)$ and $\left(\breve{q}_{2}^{r}, \breve{q}_{2}^{p}\right)=\left(\breve{q}_{2}^{u}, \breve{\Phi}-\breve{q}_{1}^{b}\right)$ where $q_{2}^{r}\left(q_{2}^{p}\right)$ denotes the consumption by a rich buyer (a poor buyer) in an unconstrainedprice equilibrium and $\breve{q}_{2}^{r}\left(\breve{q}_{2}^{p}\right)$ denotes the consumption by a rich buyer (a poor buyer) in a constrained-price equilibrium. Since $\eta>\breve{\eta}=\eta\left\{\rho_{s} \breve{q}_{2}^{u} /\left[\rho_{b}\left(\breve{\Phi}-\breve{q}_{1}\right)+\rho_{s} \breve{q}_{2}^{u}\right]\right\}, u^{\prime}\left(q_{2}^{r}\right)=u^{\prime}\left(\bar{q}_{2}\right)=$ $[1 /(1-\eta)]>[1 /(1-\breve{\eta})]=u^{\prime}\left(\breve{q}_{2}^{u}\right)=u^{\prime}\left(\breve{q}_{2}^{r}\right)$ and therefore, $\breve{q}_{2}^{r}>q_{2}^{r}$. In addition, $\breve{q}_{2}^{p}<q_{2}^{p}$ because $\breve{q}_{2}^{p}=\breve{\phi}\left(M-\breve{p}_{1} \breve{q}_{1}^{b}\right)=\breve{\Phi}-\breve{q}_{1}^{b}<\Phi-\breve{q}_{1}^{b}=\Phi-q_{1}^{b}=\phi\left(M-p_{1} q_{1}^{b}\right)=q_{2}^{p}$. 


\section{Appendix B: Additional Numerical Results}

Table 3: Constrained-price and unconstrained-price equilibrium: $\rho_{s}=0.5$

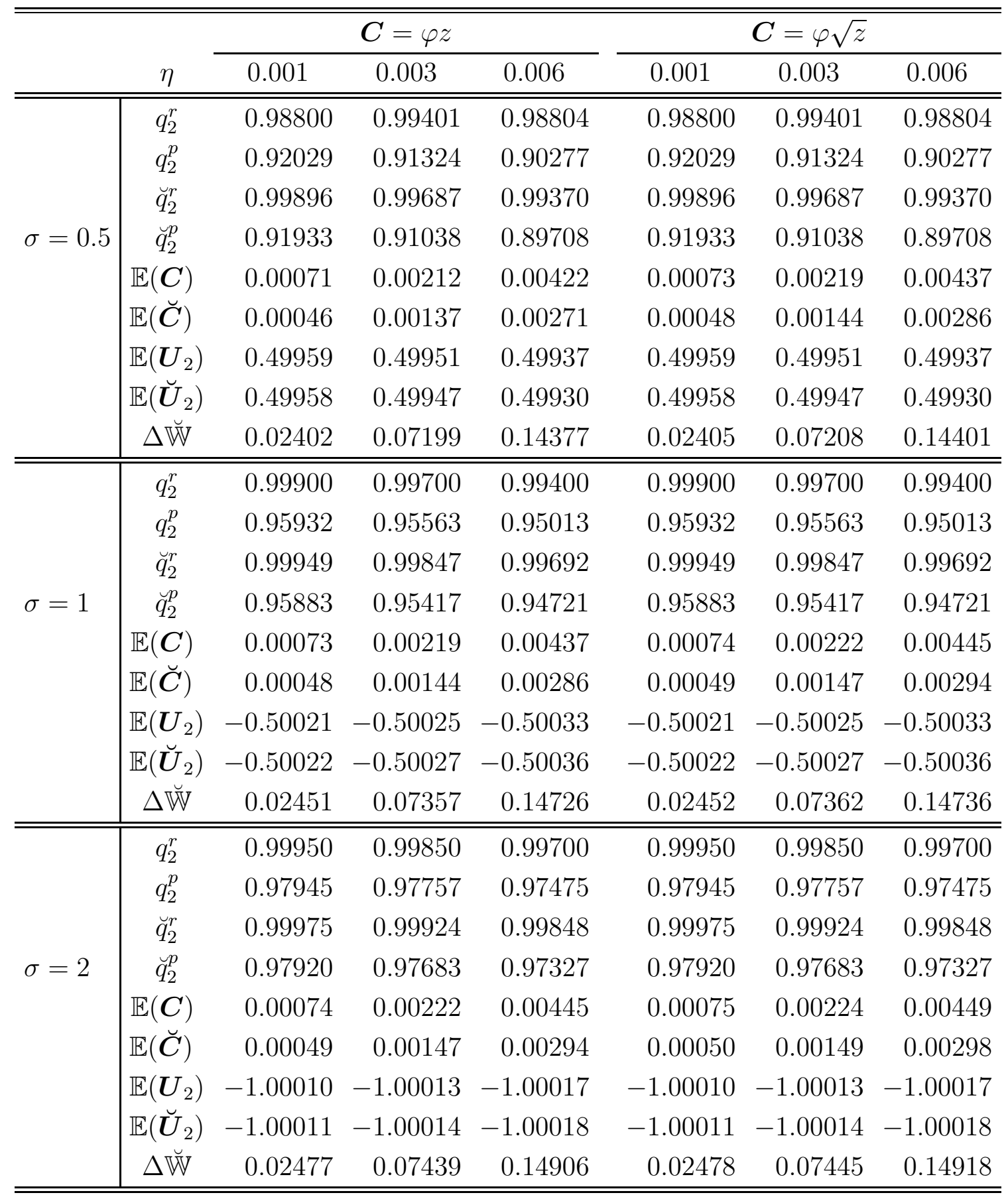




\section{References}

Aliprantis, Charalambos, Gabriele Camera, and Daniela Puzzello. (2007) "Anonymous Markets and Monetary Trading." Journal of Monetary Economics, 54, 1905-1928.

Berentsen, Aleksander, Gabriele Camera, and Christopher Waller. (2005) "The Distribution of Money Balances and the Nonneutrality of Money." International Economic Review, 46, 465-487.

Berentsen, Aleksander, Gabriele Camera, and Christopher Waller. (2007) "Money, Credit and Banking." Journal of Economic Theory, 135, 171-195.

Bolt, Wilko, Nicole Jonker, and Corry van Renselaar. (2010) "Incentives at the Counter: An Empirical Analysis of Surcharging Card Payments and Payment Behaviour in the Netherlands." Journal of Banking and Finance, 34, 1738-1744.

Borzekowski, Ron, Elizabeth Kiser, and Shaista Ahmed. (2008) "Consumers' Use of Debit Cards: Patterns, Preferences, and Price Response." Journal of Money, Credit and Banking, 40, 149-172.

Carlton, Dennis, and Alan Frankel. (1995) "The Antitrust Economics of Credit Card Networks." Antitrust Law Journal, 63, 903-915.

Chakravorti, Sujit. (2010) "Externalities in Payment Card Networks: Theory and Evidence." Review of Network Economics, 9, Article 3.

Corbae, Dean, Ted Temzelides, and Randall Wright. (2003) "Directed Search and Monetary Exchange." Econometrica, 71, 731-756.

Faig, Miquel, and Xiuhua Huangfu. (2007) "Competitive-Search Equilibrium in Monetary Economies." Journal of Economic Theory, 136, 709-718.

Freeman, Scott, and Finn Kydland. (2007) "Monetary Aggregates and Output." American Economic Review, 90, 1125-1135.

He, Ping, Lixin Huang, and Randall Wright. (2008) "Money, Banking, and Monetary Policy." Journal of Monetary Economics, 55, 1013-1024.

Humphrey, David. (2004) "Replacement of Cash by Cards in US Consumer Payments." Journal of Economics and Business, 56, 211-225.

Hunt, Robert. (2003) "An Introduction to the Economics of Payment Card Networks." Review of Network Economics, 2, 80-96.

Kim, Young Sik, Manjong Lee. (2010) "A Model of Debit Card as a Means of Payment." Journal of Economic Dynamics and Control, 34, 1359-1368.

Kocherlakota, Narayana. (1998) "Money is Memory." Journal of Economic Theory, 81, 232-251. 
Lagos, Ricardo, and Guillaume Rocheteau. (2005) "Inflation, Output and Welfare." International Economic Review, 46, 495-522.

Lagos, Ricardo, and Randall Wright. (2005) "A Unified Framework for Monetary Theory and Policy Analysis." Journal of Political Economy, 113, 463-484.

Macfarlane, Cyril. (2005) "Gresham's Law of Payment." Speech at the AIBF Industry Forum. www.bis.org/review/r050323l.pdf

Monnet, Cyril, and William Roberds. (2008) "Optimal Pricing of Payment Services." Journal of Monetary Economics, 55, 1428-1440.

Rochet, Jean-Charles and Jean Tirole. (2004) "Two-sided Markets: an Overview." IDEI working paper, University of Toulouse.

Rochet, Jean-Charles and Jean Tirole. (2006) "Externalities and Regulation in Card Payment Systems." Review of Network Economics, 5, 1-14.

Li, Yiting. (2008) "Currency and Checking Deposits as Means of Payment." Review of Economic Dynamics, 14, 403-417.

Rocheteau, Guillaume, and Randall Wright. (2005) "Money in Search Equilibrium, in Competitive Equilibrium and in Competitive Search Equilibrium." Econometrica, 73, 175-202.

Shy, Oz. (2012) "Who Gains and Who Loses from the 2011 Debit Card Interchange Fee Reform?" Federal Reserve Bank of Boston, Public Policy Discussion Papers No. 12-06.

Schuh, Scott, Oz Shy, and Joanna Stavins. (2010) "Who Gains and Who Loses from Credit Card Payments: Theory and Calibrations." Federal Reserve Bank of Boston, Public Policy Discussion Papers No. 10-03.

Schuh, Scott, and Joanna Stavins. (2012) "How Consumers Pay: Adoption and Use of Payments." Federal Reserve Bank of Boston, Working Papers No. 12-2.

Schwartz, Marius, and Daniel Vincent. (2006) "The No Surcharge Rule and Card User Rebates: Vertical Control by a Payment Network." Review of Network Economics, 5, Issue 1.

Wallace, Neil. (2001) "Whither Monetary Economics?" International Economic Review, 42, 847-870. 